\title{
Are Gastroenterologists Less Tolerant of Treatment Risks than Patients? Benefit-Risk Preferences in Crohn's Disease Management
}

\author{
F. Reed Johnson, PhD; A. Brett Hauber, PhD; Semra Özdemir, MS; \\ Corey A. Siegel, MD; Steven Hass, PhD; and Bruce E. Sands, MD
}

\begin{abstract}
BACKGROUND: Crohn's disease is a serious and debilitating gastrointestinal disorder with a high, unmet need for new treatments. Biologic agents have the potential to alter the natural course of Crohn's disease but present known risks of potential serious adverse events (SAEs). Previous studies have shown that patients are willing to accept elevated SAE risks in exchange for clinical efficacy. Gastroenterologists and patients may have similar goals of maximizing treatment benefit while minimizing risk; however, gastroenterologists may assess the relative importance of risk differently than patients.
\end{abstract}

OBJECTIVE: To (a) understand how gastroenterologists caring for patients with Crohn's disease balance benefits and risks in their treatment decisions and (b) compare their treatment preferences with those of adult patients with Crohn's disease.

METHODS: Both patient and gastroenterologist treatment preferences were elicited using a web-based, choice-format conjoint survey instrument. The conjoint questions required subjects to choose between 2 hypothetical treatment options with differing levels of treatment attributes. Patients evaluated the treatment options for themselves, and gastroenterologists evaluated the treatment options for each of 3 hypothetical patient types: (a) female aged 25 years with no history of Crohn's disease surgery (young), (b) male aged 45 years with 1 Crohn's disease surgery (middleaged), and (c) female older than 70 years with 4 Crohn's disease surgeries (older). Treatment attributes represented the expected outcomes of treatment: severity of daily symptoms, frequency of flare-ups, serious disease complications, oral steroid use, and the risks of 3 potentially fatal SAEs - lymphoma, serious or opportunistic infections, and progressive multifocal leukoencephalopathy (PML) - during 10 years of treatment. Maximum acceptable risk (MAR), defined as the highest level of SAE risk that subjects would accept in return for a given improvement in efficacy (i.e., the increase in treatment risk that exactly offsets the hypothetical increase in treatment benefit), was calculated using preference weights (parameter marginal log odds ratios) that were estimated with conjoint analysis (random parameters logit models). Gastroenterologists' and patients' mean MARs for 3 SAE risks were calculated for 6 improvements in Crohn's disease symptoms, and gastroenterologists' preference weights for each of the 3 patient profiles were compared. Gastroenterologists' MARs for a hypothetical middle-aged patient were then compared with predicted MARs derived using data from the patient study for male patients aged 40 to 50 years with 1 surgery.

RESULTS: After exclusion of nonrespondents ( $n=4,021$ of 4,422 gastroenterologists; $n=681$ of 1,285 patients) and nonevaluable respondents ( $n=86$ gastroenterologists; $n=24$ patients), 315 gastroenterologists and 580 patients were included in the final analytic samples. There were no statistically significant differences in gastroenterologists' preference weights for the middle-aged versus young patient profiles. However, preference weights indicated that gastroenterologists are more concerned about $5 \%$ side-effect risks for the older patient profile than for the middle-aged patient profile. For symptomatic improvements from severe symptoms to remission, gastroenterologists' highest MARs were for lymphoma: $6.21 \%, 8.99 \%$, and $25.00 \%$ for the young, middle-aged, and older patient types, respectively. In analyses of improvements from severe to moderate symptoms and from moderate symptoms to remission for hypothetical middle-aged patients, gastroenterologists' 10-year risk tolerance ranged between $1.96 \%$ lymphoma risk in return for an improvement from moderate symptoms to remission and $4.93 \%$ lymphoma risk for an improvement from severe to moderate symptoms; patients' 10-year risk tolerance for middle-aged patients ranged between $1.52 \%$ PML risk in return for an improvement from severe to moderate symptoms and $5.86 \%$ infection risk for an improvement from moderate symptoms to remission. On average, gastroenterologists and patients disagreed about how much risk is tolerable for improvements in efficacy. In exchange for improvements from severe to moderate symptoms for the middle-aged patient profile, gastroenterologists were significantly more tolerant than patients of treatment risks of PML $(P<0.001)$ and serious infection $(P=0.001)$ but not lymphoma $(P=0.230)$. In contrast, in exchange for improvements from moderate symptoms to remission for the same patient profile, patients were significantly more tolerant than gastroenterologists of treatment risks for serious infection $(P<0.001)$ and lymphoma $(P<0.001)$ but not PML $(P=0.158)$.

CONCLUSIONS: Gastroenterologists and patients have well-defined preferences among treatment attributes and are willing to accept tradeoffs between efficacy and treatment risks. However, risk tolerance varies depending on the type of patient for whom gastroenterologists are being asked to consider treatment. In rating treatment preferences for patients with a middle-aged profile, gastroenterologists are less tolerant of SAE risks than patients in exchange for improvement from moderate symptoms to remission.

\section{J Manag Care Pharm. 2010;16(8):616-28}

Copyright $\odot 2010$, Academy of Managed Care Pharmacy. All rights reserved.

\section{What is already known about this subject}

- Crohn's disease affects approximately one-half million patients in the United States. The age of onset ranges from early childhood to older age, but the peak incidence is in the second decade of life.

- New biologic agents, including natalizumab, infliximab, adalimumab, and certolizumab pegol, have the potential to significantly alter the natural course of Crohn's disease but present known risks of potential serious adverse events (SAEs), including lymphoma, serious or opportunistic infections, and progressive multifocal leukoencephalopathy (PML).

- A previous study using a web-enabled, choice-format conjoint survey showed that patients with Crohn's disease are willing to accept higher SAE risks in return for better treatment efficacy. For a 10-year treatment exposure, the mean tolerance for PML risks ranged between $6.3 \%$ (95\% CI $=4.1 \%-8.5 \%$ ) for reduction in severity of symptoms from severe to remission and $0.9 \%(95 \%$ $\mathrm{CI}=0.4 \%-1.6 \%)$ for reduction in severity of symptoms from mild to remission. 


\section{What this study adds}

- 315 subjects from a panel of 4,422 gastroenterologists completed a web-enabled conjoint-survey and evaluated a series of treatment tradeoff questions for 3 patient profiles. 580 of 1,285 patients who accessed the web-enabled instrument answered the same tradeoff questions as the gastroenterologist sample.

- Gastroenterologists' mean risk tolerance was higher when assessing older patients compared with middle-aged patients. For the largest symptom improvement, severe symptoms to remission, gastroenterologists' maximum acceptable risk (MAR) means for the middle-aged patient profile were 6.95\% (95\% CI $=5.90 \%$ $8.00 \%), 7.09 \%$ (95\% CI $=5.85 \%-8.33 \%)$, and $8.99 \%(95 \%$ $\mathrm{CI}=7.20 \%-10.78 \%)$ for serious infection, PML, and lymphoma, respectively. The corresponding MARs for the older patient profile were $12.40 \%$ (95\% CI $=10.19 \%-14.62 \%), 14.20 \%$ (95\% $\mathrm{CI}=11.24 \%-17.16 \%)$, and $25.00 \%$ (95\% CI $=20.65 \%-29.35 \%)$.

- In analyses of the middle-aged patient profile, the mean MARs of PML for treatments that improve symptoms from severe to moderate were $4.24 \%(95 \% \mathrm{CI}=3.22 \%-5.26 \%)$ and $1.52 \%(95 \%$ $\mathrm{CI}=0.97 \%-2.02 \%)$ for gastroenterologists and patients, respectively $(P<0.001)$, while the corresponding MAR estimates for improvements from moderate symptoms to remission were $2.09 \%$ (95\% CI $=1.44 \%-2.74 \%$ ) and $3.26 \%(95 \% \mathrm{CI}=1.76 \%-4.76 \%)$ for gastroenterologists and patients, respectively $(P=0.158)$.

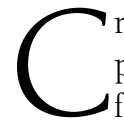
rohn's disease affects approximately one-half million patients in the United States. ${ }^{1}$ The age of onset ranges from early childhood to older age, but the peak incidence is in the second decade of life. ${ }^{2}$ The development of more effective medications $s^{3-5}$ and the recognition that Crohn's disease treatment algorithms using the immunosuppressants azathioprine and methotrexate have failed to alter disease natural history ${ }^{6}$ have led to a consideration of shifting toward more aggressive therapy earlier in the disease course ("earlyaggressive" or "top-down" therapy). ${ }^{7}$ Biologic agents have the potential to alter the natural course of Crohn's disease, but present known risks of potential serious adverse events (SAEs). ${ }^{8-11}$ Approved biologic therapies include the integrin receptor antagonist, natalizumab, and the inhibitors of tumor necrosis factor (TNF)- $\alpha$, infliximab, adalimumab, and certolizumab pegol. Although all of these biologic agents have the potential to cause adverse events, the most worrisome adverse events include lymphoma, serious or opportunistic infections, and progressive multifocal leukoencephalopathy (PML). ${ }^{8-11}$

In evaluating difficult treatment decisions, gastroenterologists must balance the benefits and risks of alternative therapies. Previous studies of maximum acceptable risk (MAR), defined as the highest level of SAE risk that subjects would accept in return for a given improvement in efficacy (i.e., the increase in treatment risk that exactly offsets treatment benefit), have shown that adult patients and parents of juvenile patients with Crohn's disease are willing to accept SAE risks in exchange for improved clinical efficacy. ${ }^{12,13}$ A previous study of adult patients with Crohn's disease found that for an improvement from severe symptoms to remission, patients were willing to accept an annual MAR of $0.70 \%$ for PML (95\% confidence interval $[\mathrm{CI}]=0.60 \%-0.80 \%), 0.73 \%$ for serious infection $(95 \%$ $\mathrm{CI}=0.66 \%-0.81 \%$ ), and $0.82 \%$ for lymphoma (95\% CI $=0.72 \%$ $0.92 \%) .{ }^{12}$ For an improvement from moderate symptoms to remission, patients were willing to accept an annual MAR of $0.39 \%$ for PML (95\% CI $=0.27 \%-0.52 \%$ ), $0.55 \%$ for serious infection (95\% CI $=0.48 \%-0.61 \%$ ), and $0.55 \%$ for lymphoma (95\% CI $=0.48 \%-0.62 \%) .{ }^{12}$ For a 10 -year treatment exposure, the mean tolerance for PML risks ranged between 6.3\% (95\% $\mathrm{CI}=4.1 \%-8.5 \%)$ for reduction in severity of symptoms from severe to remission and $0.9 \%(95 \% \mathrm{CI}=0.4 \%-1.6 \%)$ for reduction in severity of symptoms from mild to remission (unpublished analysis of reference 12 data).

Gastroenterologists and patients may have similar goals of maximizing treatment benefit while minimizing risk; however, gastroenterologists may assess the relative importance of risk differently than patients. The objectives of the present study were to understand how gastroenterologists caring for patients with Crohn's disease balance benefits and risks in their treatment decisions and to compare their preferences with those of adult Crohn's disease patients measured in a previous survey. ${ }^{12,13}$ Both the present study of gastroenterologists and the previous study of adult patients with Crohn's disease were conducted by the same research team, using the same survey instruments with differences noted below, and were funded by the same sponsors.

In both studies, to elicit preferences regarding the benefits and risks of treatments for Crohn's disease, we developed a choice-format conjoint-analysis survey (also known as a discrete-choice experiment). Conjoint analysis is a systematic method for eliciting individual preferences through a sequence of structured trade-off questions. Subjects evaluate a series of pairs of hypothetical treatment options. The observed pattern of choices reveals the underlying preference weights associated with various treatment outcomes. Using this method, the MAR of a treatment-related adverse event can be calculated for any given level of efficacy.

\section{Methods}

\section{Survey Development}

The choice-format conjoint-analysis survey instrument was developed to elicit tradeoff preferences for the most salient features or attributes of Crohn's disease treatments. These attributes were identified in a review of the literature, consultations with medical experts, and interviews with patients. Treatment attributes included 4 measures of treatment efficacy (severity of daily symptoms, frequency of flare-ups, prevention of serious disease complications, and the need for oral steroids), and the 10-year risks of 3 potentially fatal SAEs (death or severe disability from PML, death from serious 


\begin{tabular}{|c|c|c|}
\hline Treatment Features & Treatment A & Treatment B \\
\hline Severity of daily Crohn's symptoms & $\begin{array}{l}\text { Moderate } \\
\text { - Moderate pain on most days or severe pain } \\
\text { on some days } \\
\text { - About } 8 \text { or more diarrhea stools per day } \\
\text { - Generally feel poorly } \\
\text { - Considerable problems with work and leisure } \\
\text { activities }\end{array}$ & $\begin{array}{l}\text { Mild } \\
\text { - Mild pain most days } \\
\text { - About } 3 \text { diarrhea stools per day } \\
\text { - Generally feel below par } \\
\text { - Some problems with work and leisure } \\
\text { activities }\end{array}$ \\
\hline $\begin{array}{l}\text { Effect on serious complications } \\
\text { (fistulas, abscesses or bowel obstructions) }\end{array}$ & Prevents all serious complications & Reduces some of the serious complications \\
\hline Time between flare-ups & 2 years & 6 months \\
\hline Treatment requires taking oral steroids & \multicolumn{2}{|c|}{ Yes } \\
\hline $\begin{array}{l}\text { Chance of dying from a serious } \\
\text { infection within } 10 \text { years }\end{array}$ & None would die & None would die \\
\hline $\begin{array}{c}\text { Chance of dying or severe } \\
\text { disability from PML within } 10 \text { years }\end{array}$ & $\begin{array}{c}5 \text { patients out of } \mathbf{1 0 0 0}(0.5 \%) \\
\text { would die or have severe disability }\end{array}$ & None would die or have severe disability \\
\hline $\begin{array}{c}\text { Chance of dying from lymphoma } \\
\text { within } 10 \text { years }\end{array}$ & \multicolumn{2}{|c|}{ None would die } \\
\hline Which treatment would you choose? & $\begin{array}{c}\square \\
\text { Treatment A }\end{array}$ & $\begin{array}{c}\square \\
\text { Treatment B }\end{array}$ \\
\hline
\end{tabular}

infections, and death from lymphoma).

The survey instrument was pre-tested to verify understandability and salience of the ranges of efficacy and side effect risks offered. The first pre-test employed in-person cognitive interviews with 10 patients who had been diagnosed with Crohn's disease. The second pre-test was a pilot survey administered to 51 adult patients with Crohn's disease drawn from registered users of HealthTalk, an informational Web service for chronically ill patients (www.healthtalk.com).

The conjoint analysis tasks within the final survey asked patients to choose between 2 treatment options with differing treatment attributes. Figure 1 provides an example of the conjoint analysis question format. We employed a variation of a commonly-used algorithm to construct a near-optimal experimental design resulting in 45 pairs of treatment options. ${ }^{14,15}$ To reduce respondent burden, the tradeoff tasks were blocked into 5 sets of 9 questions. Each subject was randomly assigned to receive 1 of the 5 sets of questions. Each respondent also completed an additional trade-off question in which 1 treatment dominated the other treatment for every attribute to test whether respondents understood the evaluation task.

Gastroenterologists in the present study evaluated the same tradeoff questions as did patients in the patient study, ${ }^{12}$ with a few differences. The foremost difference was that gastroenterologists evaluated the tradeoff questions for 3 stereotypical patient profiles and patients evaluated the tradeoffs for themselves. Other differences between the surveys included using medical terms instead of lay language in the outcome definitions in the physician survey, dropping the risk tutorial, and replacing patient health history and treatment questions with background questions regarding the gastroenterologists, their practice, and their population of patients with Crohn's disease.

In November 2006, 1-hour pre-test telephone interviews were conducted with 10 gastroenterologists recruited through a physician panel maintained by Harris Interactive. These interviews helped to finalize the 3 stereotypical patient profiles as: (a) a female patient aged 25 years with no history of Crohn's disease surgery (young), (b) a male patient aged 45 years with 1 Crohn's disease surgery (middle-aged), and (c) a female patient older than age 70 years with 4 Crohn's disease surgeries (older). Time since diagnosis was originally included in each patient profile, but this patient characteristic was deleted from the final survey because gastroenterologists were insensitive to that characteristic or assumed that it was correlated with age.

The final gastroenterologist survey instrument included 4 sections: (a) questions about each gastroenterologists' experience and practice, (b) descriptions of the attributes included in the choice questions and the hypothetical stereotypical patients to be considered, (c) the conjoint choice questions, and (d) a series of follow-up questions designed to elicit subjects' views on the difficulty of understanding and completing the conjoint choice tasks.

\section{Survey Sample and Administration}

Both the patient and physician surveys were programmed for web-based administration by MRxHealth (Seattle, WA). The web-based survey instrument was administered to patients with Crohn's disease during the period from September 2005 to January 2006. The patients were recruited from 3 sources: members of the HealthTalk chronic-disease web site, patients at clinical practice sites who had participated in a 
natalizumab clinical trial, and patients at the same sites who had not participated in the clinical trial. All patients were aged 18 years or older and provided informed consent to participate in the survey in exchange for a $\$ 20$ donation to the Crohn's $\&$ Colitis Foundation of America (New York, NY). The survey was approved by the Research Triangle Institute (RTI) Office of Research Protection and Ethics. ${ }^{12}$

The gastroenterologist survey was administered between December 2006 and April 2007. The gastroenterologist sample was identified from databases maintained by MRxHealth and by the Epocrates QuickRecruit service. MRxHealth maintains a peer group of over 500,000 U.S. medical professionals who voluntarily participate in surveys and web-based discussions. The Epocrates Honors Panel consists of 134,000 opted-in and verified U.S. gastroenterologists. There were 2,540 and 2,301 gastroenterologists enrolled in the MRxHealth and Epocrates panels, respectively, for a total of 4,841 at the time of this study. Participants were required to be currently practicing, U.S. board-certified (or board-eligible) gastroenterologists involved in treating patients with Crohn's disease (self-reported). Each gastroenterologist received $\$ 75$ as compensation for his or her participation. The Office of Research Protection and Ethics at RTI granted an exemption for this study.

\section{Survey Validation}

In both the gastroenterologist and patient surveys, the design of the conjoint choice questions provided subject-level internalvalidity tests. Validity of the choice data was assessed by transitivity and logic tests. Transitivity requires that if subjects indicate they prefer treatment A to treatment B at one point in the question sequence and indicate they prefer treatment $\mathrm{B}$ to treatment $C$ at another point, then they also should prefer treatment A to treatment $C$ in a third question. The logic test determined whether subjects could identify the correct treatment when one treatment alternative was unambiguously better than the other alternative in every respect. Failure to pass one of these tests does not necessarily invalidate all the subjects' responses; we tested whether model fit was better when subjects with test failures were included or excluded.

\section{Statistical Analysis}

In discrete choice experiments, the pattern of choices observed from correctly designed experimental stimuli reveals the implicit decisions or preference weights employed by subjects in evaluating the hypothetical treatment tradeoffs in a conjoint survey. Choice questions generate cross-section/time-series data that require analysis using advanced statistical techniques. We used random-parameters logit (RPL, also described as mixed logit, random coefficients logit, or error-components logit) to analyze the survey preference data. Unobserved variation in preferences across the sample can bias estimates in conventional conditional-logit choice models. RPL avoids this potential estimation bias by estimating a distribution of preferences around each model parameter that accounts for variations among individual preferences not accounted for by the variables in the model. ${ }^{16,17}$ The flexible correlation structure of RPL also accounts for within-sample correlation in the randomized question sequence for each subject.

RPL is similar to the conditional logit model, except that the estimated vector of parameters, $\beta$, is modified to include a subject-specific stochastic component, $\eta$, as follows:

$$
U_{j t}^{i}=V_{j t}^{i}+\varepsilon_{j t}^{i} \equiv \sum_{k=1}^{K}\left(\beta_{k j t}^{i}+\eta_{k j t}^{i}\right)+\varepsilon_{j t}^{i}
$$

where $U_{j t}^{i}, j=1, \ldots, \mathrm{J}$ is the individual subject's conjoint utility for each of $\mathrm{J}$ alternative choice alternatives in each sequence of questions, $t=1,2, \ldots, \mathrm{T}, V_{j t}^{i}$ is the determinate part of the utility of alternative $j, \beta_{k j t}^{i}$ is the categorical relative preference weight for the level of attribute $k, k=1, \ldots, K$ shown in alternative $j$, question $\mathrm{t}$; and $\varepsilon$ denotes the random-error term. Assuming that $\varepsilon$ is distributed type 1 extreme value, the probability of observing a particular sequence of choices in $\mathrm{T}$ choice questions with J alternatives is:

$$
\operatorname{Prob}\left[C_{j 1}^{i}, \ldots, C_{j \mathrm{~T}}^{i}\right]=\prod_{t=1}^{T}\left[\frac{\exp \left[\sum_{k=1}^{K}\left(\beta_{k j t}^{i}+\eta_{k j t}^{i}\right)\right]}{\sum_{j=1}^{J} \exp \left[\sum_{k=1}^{K}\left(\beta_{k j t}^{i}+\eta_{k j t}^{i}\right)\right]}\right]
$$

For any pair of treatment profiles A and B with attribute levels indexed by $\mathrm{k}$, the mean choice probability is logit:

$$
\operatorname{Prob}\left(C_{j}^{i}\right)=\frac{1}{1+\exp \left(\sum_{k} \beta_{k A}-\sum_{k} \beta_{k B}\right)}
$$

and the mean odds ratio (OR) for any 2 treatment profiles is $\exp \left(\sum \beta_{k A}-\sum \beta_{k B}\right)$. Effects coding (e.g., for a 3-level attribute: 0 $1,10,-1-1$, such that the parameter for the omitted category is the negative sum of the included categories) ${ }^{18}$ is used instead of dummy coding (e.g., $01,10,0$ ) so that the mean effect for each attribute is normalized at zero instead of setting all the omitted categories to zero. Thus the OR for any profile A relative to a profile with all attributes set to the mean effect is $\exp \left(\sum \beta_{k A}\right)$, and the marginal OR for the difference between a given attribute $\mathrm{k}$, level $\mathrm{j}$ and the mean effect within an attribute is $\exp \left(\beta_{k j}\right)$. Finally, the log odds for a given attribute $\mathrm{k}$, level $\mathrm{j}$ is $\beta_{k j}$, the preference weight.

The resulting mean preference weights were used to estimate MAR. For example, assuming that A and B are outcome profiles with zero therapeutic risk and $A$ is the preferred outcome, $V_{A}>V_{B}$, and the ORs for increasing values of a therapeutic risk $\mathrm{R}$ are calculated as: $\mathrm{OR}=\exp \left[\sum \beta_{\mathrm{iA}}-\left(\sum \beta_{\mathrm{i} B}+\beta_{R} \cdot R\right)\right]$. MAR is the value of $R$ that makes $O R=1$. In practice, risk attributes are estimated as categorical to avoid imposing any functionalform assumption. Finding the level of risk that makes $\mathrm{OR}=1$ thus requires linear interpolation between categorical risk-level parameters.

Figure 2 illustrates this calculation. The preference-weight OR for moderate symptoms versus severe symptoms with zero 
therapeutic risk for both is the vertical intercept in the figure. In this example, OR was plotted holding risk at zero for severe symptoms but varying treatment risk between $0 \%$ and $5 \%$ for moderate symptoms. The plot crosses $\mathrm{OR}=1$ at $2 \%$, so maximum acceptable risk is $2 \%$. In other words, MAR is the increase in treatment risk that exactly offsets the therapeutic benefit of a given improvement in treatment outcomes and indicates the maximum level of treatment-related risk that subjects are willing to accept for a given improvement in disease symptoms or outcomes. ${ }^{14,19}$ In the present study, gastroenterologists' MARs were calculated for 6 treatment benefit (efficacy) levels (e.g., severe symptoms to remission, severe symptoms to mild symptoms) for each of the 3 hypothetical patient profiles and each of the 3 potentially fatal SAEs. Additionally, gastroenterologist and middle-aged patient MARs were calculated for each SAE for 2 levels of improvement in symptom severity: from severe to moderate symptoms and from moderate symptoms to remission.

In any choice-format conjoint survey, some subjects dominate on a single attribute; that is, they always choose the alternative with the better level of the most important (dominant) attribute, regardless of the levels of the other attributes presented in the choice question. There are 2 reasons why subjects might answer the choice questions in this way. First, these choices may reflect subjects' true preferences, and the choices presented in the survey do not include combinations of other attributes that are sufficiently attractive to induce subjects to choose an alternative that does not include the better level of the dominant attribute. Alternatively, subjects simply may focus on only a single attribute as a way of simplifying the task of answering the trade-off questions. In the latter case, their choices will overstate the relative actual mean importance of the dominant attribute. To control for this behavior, we included a dummy-variable interaction term in the RPL model in which the levels of the dominant attribute were multiplied by 1 for subjects who dominated on that attribute, zero otherwise.

Overall joint tests of parameter differences employed the scale-controlled likelihood-ratio test for choice models derived by Swait and Louviere. ${ }^{20}$ Tests of differences of MARs employed 2-tailed z-tests for differences of means for independent, normally distributed random variables. Pearson chi-square tests were used to test differences in distributions of categorical variables. Statistical differences between individual parameter estimates were tested using maximum-likelihood asymptotic 2 -tailed tests at the 95\% confidence level. All statistical analyses were conducted using Gauss version 7.0 (Aptech Systems, Inc., Black Diamond, WA).

\section{Statistical Analysis of Patient Data}

The same modeling strategy was used for both the gastroenterologist sample and the previously published patient study. However, a valid comparison between gastroenterologist and patient preferences requires calibrating patient estimates with one of the patient profiles in the gastroenterologist survey. We thus estimated a new model using data from the previ-

\section{FIGURE 2 Moderate Symptoms with Treatment Risk Versus Severe Symptoms with No Treatment Risk, Odds Ratios}

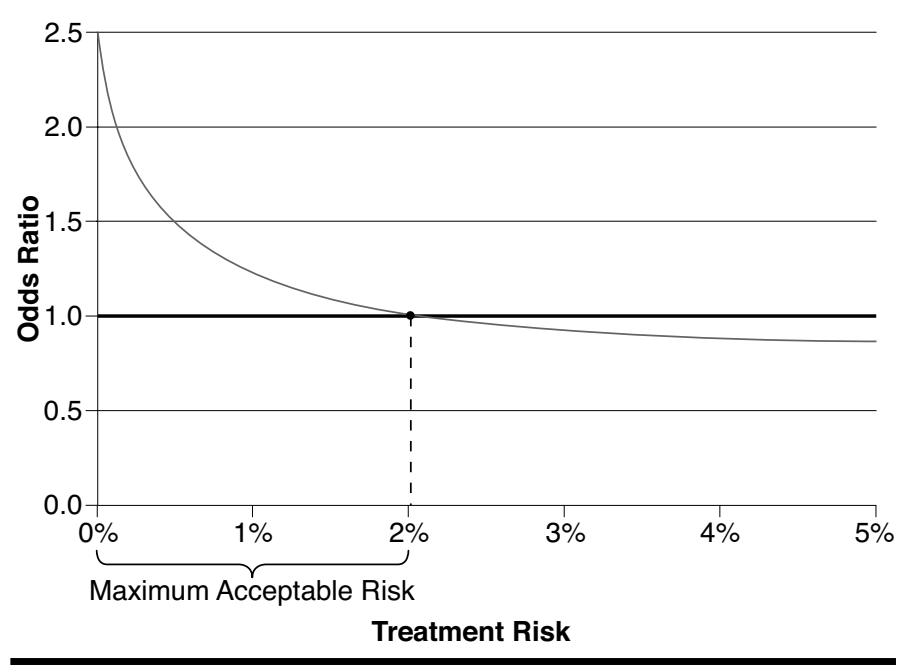

ous patient study that identifies patient preference weights corresponding to the middle-aged patient profile. This model interacts risk levels with 5 dummy variables: females, age younger than 40 years, age older than 50 years, surgeries $=0$, and surgeries $>1$. The omitted categories thus correspond to males, aged 40 to 50 years, and 1 surgery-the characteristics of the middle-aged patient profile.

\section{Results}

\section{Gastroenterologist Sample}

Of the 4,841 invitations that were sent to gastroenterologists, 4,422 (91.3\%) were deliverable. Of the 4,422 gastroenterologists who received invitations, 401 (9.1\%) completed the survey. Of 401 responding gastroenterologists, 86 who had no variation in their answers to the questions (i.e., always chose Medication A or $B, n=14)$, or who failed the logic test $(n=72)$ were excluded from the analysis sample.

Table 1 presents the characteristics of the 315 gastroenterologists included in the analysis. The mean age and years in practice were 48 and 15 years, respectively. The majority of the gastroenterologists in the sample (80.3\%) had an office-based private practice. They saw a mean of 29 patients with Crohn's disease in a typical month. We also compared their characteristics with those of the 86 gastroenterologists who were excluded from the sample to investigate any differences between the 2 groups. Gastroenterologists who were dropped from the sample were younger $(P=0.036)$, had fewer patients with mild Crohn's disease $(P=0.017)$ but more patients with severe Crohn's disease $(P=0.004)$, and had more patients receiving short-course steroid treatment $(P=0.004)$. The proportion of gastroenterologists who thought that the risk levels in the 


\section{TABLE 1 Summary of Gastroenterologist Characteristics}



conjoint questions were difficult to understand was significantly higher among gastroenterologists who were excluded from the sample than among those who were included in the analysis $(P=0.004)$. Using Pearson chi-square tests, there were no significant differences in the distributions of responses between the 2 groups in responses to the question "If you were thinking about prescribing a medication where the chance of dying from [serious infection, PML, or lymphoma] was 10 patients out of 1,000 patients (1\%), how concerned would you be about prescribing this medication?" ( $P>0.50$ for all 3 SAEs).

\section{Patient Sample}

Of the 1,007 patients who accessed the HealthTalk webenabled instrument, 357 (35.5\%) completed the survey. Exclusion of 13 patients who did not answer all of the conjoint tradeoff questions and 2 patients who had no variation in their choices (i.e., always picked only treatment A or treatment B) resulted in an analysis sample of 342 patients in the natalizumab naïve Internet panel. Of the 278 patients who were enrolled from a clinical practice site, $247(88.8 \%)$ completed the survey. Of these patients, 9 (3.6\%) failed data quality tests. 


\section{FIGURE 3 Gastroenterologist Preference Weights for Middle-Aged Patient, ${ }^{2}$} Parameter Log Odds Ratios Relative to Mean Effect $(=0)^{\mathrm{b}}$

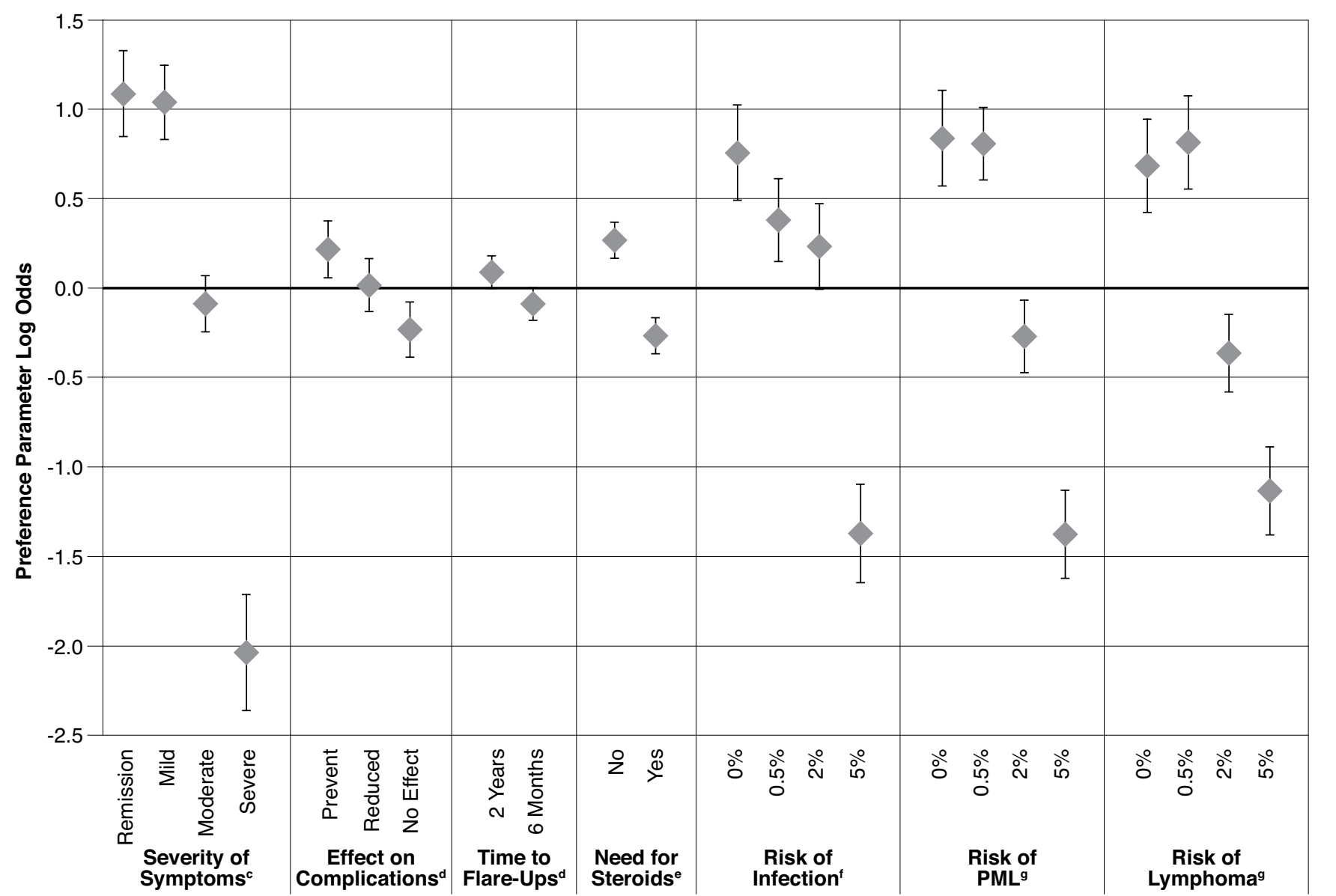

aMiddle-aged patient was defined in the gastroenterologist survey as a male aged 45 years with 1 previous Crohn's disease surgery.

${ }^{b}$ Vertical lines around the preference parameter log odds are 95\% confidence intervals. Significance tests compared log odds ratios relative to the mean effect (P<0.05).

cSignificantly differed between mild, moderate, and severe symptoms, but not between remission of symptoms and mild symptoms.

${ }^{d}$ No significant differences.

eSignificant difference between yes and no.

fSignificant difference between $2 \%$ and $5 \%$ risk but not between no risk, $0.5 \%$, and $2 \%$ risk.

sSignificant difference between $0.5 \%, 2 \%$, and $5 \%$ risk but not between no risk and $0.5 \%$ risk.

$P M L=$ progressive multifocal leukoencephalopathy.

Exclusion of these patients resulted in an analysis sample of 140 patients in the natalizumab naive patient panel and 98 patients in the natalizumab patient panel, for a total patient sample size of 580 .

Details of this sample selection process and characteristics of the patient sample have been published previously. ${ }^{12}$ The mean (SD) age was 43.6 (13.1) years, mean years of education were 15.7 (2.6), and mean household income was $\$ 75,000$ $(\$ 46,700)$. The sample was predominantly female $(68.3 \%)$ and white (93.8\%). Patients had a mean (SD) of 1.5 (2.1) surgeries that were related to their Crohn's disease. The majority (66.0\%) had been diagnosed for at least 6 years, with $46.6 \%$ diagnosed for more than 10 years and only $10.7 \%$ diagnosed within the previous 2 years. When asked about their general well-being during the last 7 days, $80.7 \%$ of patients reported feeling well or just below par, and $19.1 \%$ reported feeling poor, very poor, or terrible.

\section{Internal Validity Tests}

When considering the young, middle-aged, and older patient profiles, respectively, approximately $9 \%, 8 \%$, and $11 \%$ of gastroenterologists failed the transitivity test and 12\%, 9\%, and 
FIGURE 4 Gastroenterologist Preference Weights, Middle-Aged Patient Profile Versus Younger and Older Patient Profiles, ${ }^{a}$ Odds Ratios ${ }^{b}$

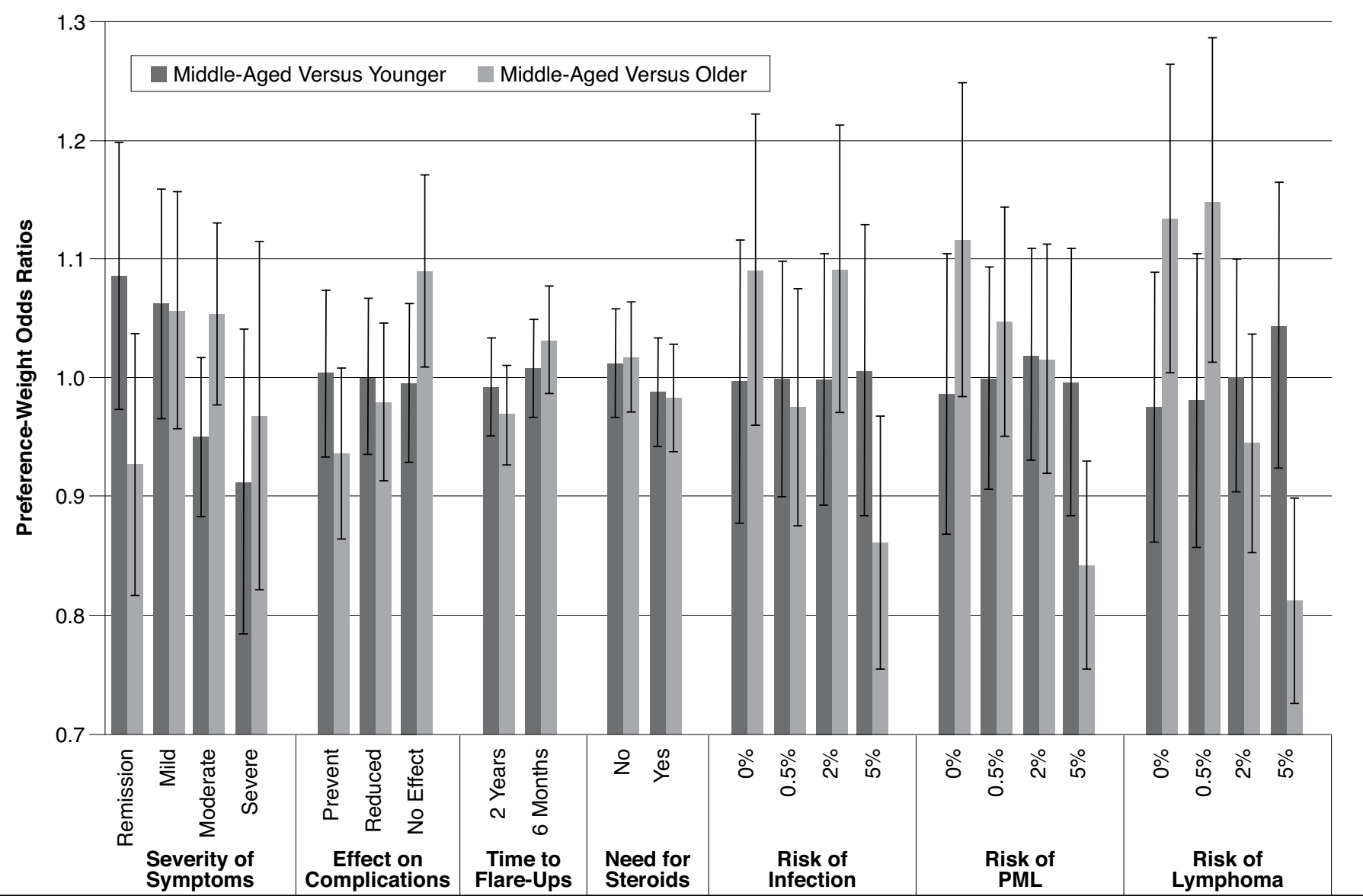

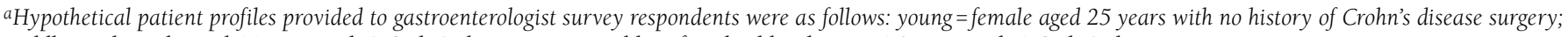
middle-aged = male aged 45 years with 1 Crohn's disease surgery; older =female older than age 70 years with 4 Crohn's disease surgeries.

bVertical lines around the preference-weight odds ratios are $95 \%$ confidence intervals.

$P M L=$ progressive multifocal leukoencephalopathy.

$12 \%$ of gastroenterologists failed the logic test. Using a standard 2-tailed z-test for difference of means, none of the failure rates was significantly different among patient profiles $(P>0.05$ for all). Excluding gastroenterologists who failed the logic test improved the precision of the point estimates. The final model also used dummy-variable interactions to control for physicians who dominated on a single attribute.

About $8 \%$ of patients failed the transitivity test and $13 \%$ of patients failed the logic test. ${ }^{12,13}$ Including all patients and using the same dummy-variable interactions as the gastroenterologist model to control for patients who dominated on a single attribute provided the best model fit.

\section{Preference-Weight Odds Ratios}

The parameter marginal log ORs from RPL models can be interpreted as relative preference weights indicating the relative strength of preference for each attribute level. Figure 3 shows gastroenterologist preference weight log ORs relative to the mean attribute effect $(=0)$ for the middle-aged patient profile. Larger preference weights indicate preferred outcomes. The estimates for all 8 attributes generally were consistent with the natural ordering of the categories within attributes. Within the symptom-severity attribute, less severe symptoms were preferred to more severe symptoms. Likewise, preference weights were significantly larger for fewer complications, fewer flareups, and avoiding the use of oral steroids than for the other levels within the complications, flare-up, and steroid attributes, respectively. Similarly, within each risk type, estimated preference weights generally were larger for lower SAE risks. The exception is that the 2 lowest risk levels for lymphoma were disordered, but the difference was insignificant. The difference 
FIGURE 5 Preference Weights of Gastroenterologists for Hypothetical Middle-Aged Patient Profile Versus Middle-Aged Patient Preference Weights, ${ }^{a}$ Odds Ratios ${ }^{b}$

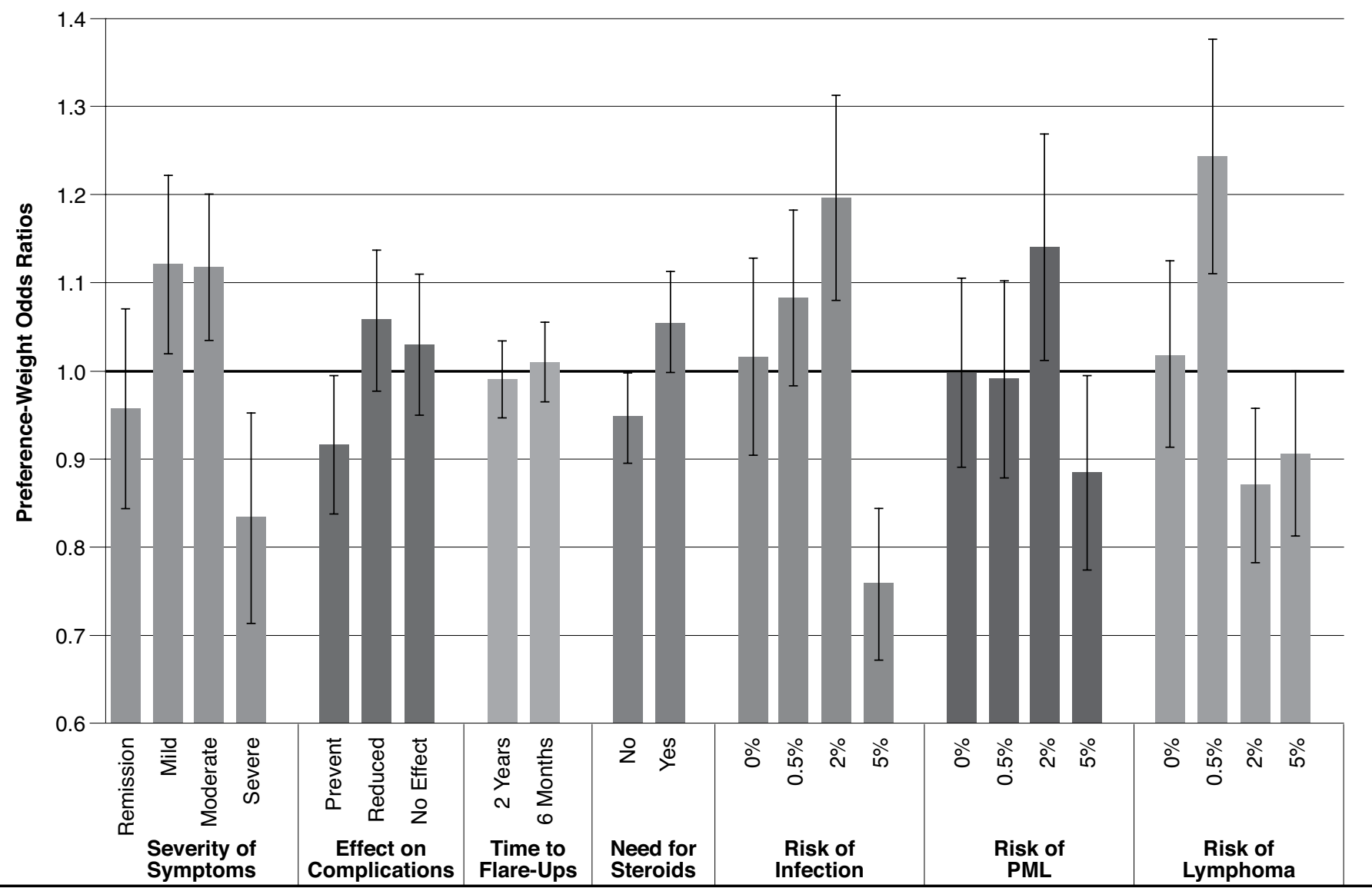

aMiddle-aged patient was defined in the gastroenterologist survey as a male aged 45 years with 1 previous Crohn's disease surgery. Preference weights for middle-aged patients in the patient survey represent male patients aged 40 to 50 years with 1 previous surgery and were estimated using random-parameter logit modeling of the patient choice data.

${ }^{b}$ Vertical lines around the preference-weight odds ratios are 95\% confidence intervals. Preference weights on the attributes significantly differed (P <0.05) for severe symptoms; prevent complications; no need for steroids; $5 \%$ risk of infection, PML, and lymphoma; and $2 \%$ risk of lymphoma.

$P M L=$ progressive multifocal leukoencephalopathy.

between the 2 lowest levels for PML also was insignificant.

Figure 4 provides OR tests for the differences in preference weights between the middle-aged patient profile and younger and older profiles, respectively. Preference weights for the middle-aged and younger patient profiles did not significantly differ on any attribute. Comparing the middle-aged and older patient profiles, there were no significant differences for the severity, flare-up, or steroid attributes, but gastroenterologists were significantly more concerned about $5 \%$ risks for all 3 side effects $(P=0.011, P<0.001$, and $P<0.001$, respectively) in older patients than in middle-aged patients.

A likelihood-ratio chi-square test used for choice models failed to reject similar preferences for the 3 patient subsamples (HealthTalk, natalizumab-naive, and natalizumab clinical trial), and the patient data were pooled for further analysis. We tested for preference heterogeneity using the individual characteristic variables for which we had data, including patients' gender, number of surgeries, and age. Based on asymptotic t-tests, the estimated parameters for female and number of surgery dummies were not statistically different than the omitted male and 1-surgery categories. Only the age categories were statistically significant in explaining risk tolerance. Thus, the final patient model corresponding to the middle-aged patient profile used for comparisons with the gastroenterologist estimates uses the estimated risk preferences for male subjects aged 40-50 years who have had 1 surgery.

Figure 5 compares preference-weight ORs for gastroenterologists relative to patients. A number of statistically 
TABLE 2 Gastroenterologists' Maximum Acceptable 10-Year Risk by Patient Profile for 6 Treatment Benefit Levels ${ }^{a}$

\begin{tabular}{|c|c|c|c|c|c|}
\hline \multirow[b]{2}{*}{$\begin{array}{l}\text { Symptom-Improvement } \\
\text { Benefit }\end{array}$} & \multicolumn{3}{|c|}{ MAR } & \multicolumn{2}{|c|}{$P$ Values } \\
\hline & Younger Patient ${ }^{\mathrm{b}}$ & Middle-Aged Patient ${ }^{b}$ & Older Patient ${ }^{\mathrm{b}}$ & \begin{tabular}{|c|} 
Middle-Aged \\
Versus Younger
\end{tabular} & $\begin{array}{l}\text { Middle-Aged } \\
\text { Versus Older } \\
\end{array}$ \\
\hline \multicolumn{6}{|l|}{ PML } \\
\hline Severe to remission & $5.64 \% \quad(4.57 \%-6.71 \%)$ & $(5.85 \%-8.33 \%)$ & $14.20 \%(11.24 \%-17.16 \%)$ & 0.082 & $<0.001$ \\
\hline Severe to mild & $5.68 \% \quad(4.66 \%-6.70 \%)$ & $(5.81 \%-8.15 \%)$ & $12.00 \% \quad(9.33 \%-14.67 \%)$ & 0.102 & 0.001 \\
\hline Severe to moderate & $3.72 \% \quad(2.67 \%-4.77 \%)$ & $(3.22 \%-5.26 \%)$ & $(3.79 \%-8.41 \%)$ & 0.486 & 0.149 \\
\hline Moderate to remission & $(1.01 \%-1.77 \%)$ & $(1.44 \%-2.74 \%)$ & $5.00 \% \quad(3.10 \%-6.90 \%)$ & 0.069 & 0.005 \\
\hline Moderate to mild & $(1.08 \%-1.75 \%)$ & $(1.46 \%-2.52 \%)$ & $2.70 \% \quad(1.38 \%-4.02 \%)$ & 0.070 & 0.328 \\
\hline Mild to remission & $0.13 \% \quad(-0.45 \%-0.71 \%)$ & $0.52 \% \quad(-0.14 \%-1.18 \%)$ & $1.20 \% \quad(0.69 \%-1.71 \%)$ & 0.383 & 0.110 \\
\hline \multicolumn{6}{|l|}{ Serious infection } \\
\hline Severe to remission & $5.77 \% \quad(4.84 \%-6.70 \%)$ & $6.95 \% \quad(5.90 \%-8.00 \%)$ & $12.40 \%(10.19 \%-14.62 \%)$ & 0.099 & $<0.001$ \\
\hline Severe to mild & $5.81 \% \quad(4.92 \%-6.70 \%)$ & $6.85 \% \quad(5.86 \%-7.84 \%)$ & $10.70 \% \quad(8.71 \%-12.69 \%)$ & 0.126 & 0.001 \\
\hline Severe to moderate & $4.36 \% \quad(3.69 \%-5.03 \%)$ & $4.65 \% \quad(3.91 \%-5.39 \%)$ & $6.30 \% \quad(4.63 \%-7.97 \%)$ & 0.568 & 0.076 \\
\hline Moderate to remission & $2.38 \% \quad(1.63 \%-3.13 \%)$ & $(2.58 \%-3.70 \%)$ & $5.50 \% \quad(4.13 \%-6.87 \%)$ & 0.112 & 0.002 \\
\hline Moderate to mild & $2.41 \% \quad(1.85 \%-2.97 \%)$ & $3.06 \% \quad(2.56 \%-3.56 \%)$ & $3.90 \% \quad(2.96 \%-4.84 \%)$ & 0.089 & 0.120 \\
\hline Mild to remission & $0.03 \% \quad(-0.24 \%-0.30 \%)$ & $0.07 \% \quad(-0.26 \%-0.40 \%)$ & $1.70 \% \quad(0.39 \%-3.01 \%)$ & 0.853 & 0.018 \\
\hline \multicolumn{6}{|l|}{ Lymphoma } \\
\hline Severe to remission & $(4.77 \%-7.66 \%)$ & $8.99 \% \quad(7.20 \%-10.78 \%)$ & $25.00 \%(20.65 \%-29.35 \%)$ & 0.018 & $<0.001$ \\
\hline Severe to mild & $(4.91 \%-7.64 \%)$ & $8.83 \% \quad(7.13 \%-10.53 \%)$ & $21.90 \%(17.82 \%-25.98 \%)$ & 0.021 & $<0.001$ \\
\hline Severe to moderate & $3.87 \% \quad(2.67 \%-5.07 \%)$ & $4.93 \% \quad(3.46 \%-6.40 \%)$ & $13.10 \% \quad(9.31 \%-16.89 \%)$ & 0.274 & $<0.001$ \\
\hline Moderate to remission & $1.40 \% \quad(1.05 \%-1.75 \%)$ & $1.96 \% \quad(1.25 \%-2.68 \%)$ & $10.40 \% \quad(7.49 \%-13.31 \%)$ & 0.167 & $<0.001$ \\
\hline Moderate to mild & $(1.12 \%-1.72 \%)$ & $1.90 \% \quad(1.36 \%-2.44 \%)$ & $6.70 \% \quad(4.18 \%-9.22 \%)$ & 0.129 & $<0.001$ \\
\hline Mild to remission & $0.52 \% \quad(-0.13 \%-1.17 \%)$ & $0.56 \% \quad(-0.11 \%-1.23 \%)$ & $1.80 \% \quad(0.80 \%-2.80 \%)$ & 0.933 & 0.043 \\
\hline \multicolumn{6}{|c|}{$\begin{array}{l}\text { bHypothetical patient profiles provided to gastroenterologist survey respondents were as follows: young =female aged } 25 \text { years with no history of Crohn's disease surgery; } \\
\text { middle-aged = male aged } 45 \text { years with } 1 \text { Crohn's disease surgery; older=female older than age } 70 \text { years with } 4 \text { Crohn's disease surgeries. } \\
\text { MAR=maximum acceptable risk; } P M L=\text { progressive multifocal leukoencephalopathy. }\end{array}$} \\
\hline
\end{tabular}

significant differences between gastroenterologist and patient preferences were noted. Patients judged severe symptoms to be relatively more important than gastroenterologists $(\mathrm{OR}=0.83$, 95\% CI $=0.71-0.95$ ), whereas gastroenterologists judged mild and moderate symptoms to be relatively more important than patients $(\mathrm{OR}=1.12,95 \% \mathrm{CI}=1.02-1.22$ and $\mathrm{OR}=1.11$, 95\% CI $=1.03-1.20$, respectively). Patients cared more about preventing complications $(\mathrm{OR}=0.92,95 \% \mathrm{CI}=0.84-1.00)$ and avoiding steroids (OR $=0.95,95 \% \mathrm{CI}=0.90-1.00)$ than gastroenterologists did.

The results on the relative importance of side effect risks between gastroenterologists and patients are mixed. Gastroenterologists were more tolerant of $2 \%$ side effect risks than patients for infection risk and PML risk, but patients were more tolerant of $2 \%$ side effect risk of lymphoma. The corresponding ORs for $2 \%$ side effect risk of serious infection, PML, and lymphoma were 1.20 (95\% CI = 1.08-1.31), 1.14 (95\% $\mathrm{CI}=1.01-1.27$ ), and 0.87 (95\% $\mathrm{CI}=0.78-0.96)$, respectively. Patients were more tolerant of $5 \%$ side effect risks than gastroenterologists for all 3 risk types. The corresponding ORs for 5\% side effect risk of serious infection, PML, and lymphoma were 0.76 (95\% CI =0.67-0.84), 0.89 (95\% CI=0.78-0.99), and 0.91 (95\% CI $=0.81-1.00$ ), respectively. While these findings appear ambiguous for answering the question of whether gastroenterologists are more or less tolerant of side effect risks than patients, the answer is clearer when we evaluate how much risk each group is willing to tolerate for treatments that yield specified improvements in symptom severity.

\section{Maximum Acceptable Risk}

Table 2 reports MAR estimates for gastroenterologists rating each SAE risk for 6 improvements in treatment efficacy. For each SAE and efficacy improvement case, gastroenterologists' MAR estimates were smallest for the younger patient profile and largest for the older patient profile. However, differences between the middle-aged patient profile and the younger-patient profile were significant in only 2 of the 18 cases. Differences between the middle-aged patient profile and the older patient profile were significant in 13 of the 18 cases overall, including all of the lymphoma cases but only 3 of the 6 PML cases. For the largest symptom improvement, severe symptoms to remission, MARs for the middle-aged patient profile were 6.95\%, 7.09\%, and $8.99 \%$ for serious infection, PML, and lymphoma, respectively. The corresponding MARs for the older patient profile were $12.40 \%, 14.20 \%$, and $25.00 \%$ (all comparisons of middleaged vs. older patient profiles $P<0.001)$. For an improvement 
from severe symptoms to remission, the lymphoma MARs for the younger patient profile and the middle-aged patient profile were $6.21 \%$ and $8.99 \%$, respectively $(P=0.018)$.

Table 3 compares gastroenterologists' and patients' MARs for the 3 SAEs for each of 2 improvements in symptom severity for middle-aged patients. For physicians, 10-year risk tolerance ranged between $1.96 \%$ lymphoma risk in return for an improvement from moderate symptoms to remission and $4.93 \%$ lymphoma risk for an improvement from severe to moderate symptoms. For patients, 10 -year risk tolerance ranged between $1.52 \%$ PML risk in return for an improvement from severe to moderate symptoms and $5.86 \%$ infection risk for an improvement from moderate symptoms to remission. On average when rating treatments for a hypothetical middle-aged patient, compared with respondents in the patient sample, gastroenterologists were willing to accept significantly higher levels of risk of serious infection and PML, but not lymphoma, in return for an improvement from severe to moderate symptoms. Compared with gastroenterologists, patients were willing to accept significantly higher levels of risk of serious infection and lymphoma, but not PML, in return for an improvement from moderate symptoms to remission.

\section{Discussion}

As expected, gastroenterologists' and patients' choices in these studies indicate a systematic preference for treatments that provide better efficacy and lower SAE risks. Models of these choices indicate how much SAE risk gastroenterologists are willing to accept in return for specific improvements in efficacy. For example, for a treatment offering a decrease in symptom severity from severe to remission to a patient aged 25 years with no previous Crohn's disease surgeries, the mean gastroenterologist 10-year MAR for severe disability or death due to PML was $5.64 \%$. For the same symptomatic improvement, gastroenterologists' risk tolerance for PML was approximately twice as high for the older patient profile compared with the middle-aged patient profile ( $14.20 \%$ vs. $7.09 \%$, respectively; $P<0.001$ ).

A notable finding is that, on average, gastroenterologists and patients disagree about how much risk is tolerable for all 3 SAEs for improvements in efficacy. For middle-aged patients, gastroenterologists are significantly more tolerant of treatment risks for improvements from severe to moderate symptoms for serious infection and PML, but not lymphoma. In contrast, corresponding patients are significantly more tolerant of treatment risks for improvements from moderate symptoms to remission for serious infection and lymphoma, but not PML. While there are differences in the relative weights gastroenterologists and patients assign to different kinds and magnitudes of risks, an important reason for the difference appears to be the different weights that gastroenterologists and patients assign to improvements in moderate symptoms.

A developing dilemma in the treatment of Crohn's disease is
TABLE 3 Maximum Acceptable 10-Year Risk: Gastroenterologists Versus Patients

\begin{tabular}{|c|c|c|c|c|}
\hline \multirow[b]{2}{*}{$\begin{array}{l}\text { Side Effect } \\
\text { Risk }^{a}\end{array}$} & \multirow[b]{2}{*}{$\begin{array}{c}\text { Symptom } \\
\text { Improvement }\end{array}$} & \multicolumn{2}{|c|}{ Maximum Acceptable Risk } & \multirow[b]{2}{*}{$\begin{array}{c}P \\
\text { Value }^{\mathrm{d}}\end{array}$} \\
\hline & & $\begin{array}{c}\text { Gastroenterologist } \\
\text { Ratings for } \\
\text { Middle-Aged } \\
\text { Patient Profile }\end{array}$ & $\begin{array}{c}\text { Middle-Aged } \\
\text { Patients }^{c}\end{array}$ & \\
\hline \multirow{4}{*}{$\begin{array}{l}\text { Serious } \\
\text { infection }\end{array}$} & \multirow{2}{*}{$\begin{array}{l}\text { Severe to } \\
\text { moderate }\end{array}$} & $4.65 \%$ & $2.00 \%$ & \multirow{2}{*}{0.001} \\
\hline & & $(3.91 \%-5.39 \%)$ & $(0.50 \%-3.50 \%)$ & \\
\hline & \multirow{2}{*}{$\begin{array}{l}\text { Moderate to } \\
\text { remission }\end{array}$} & $3.14 \%$ & $5.86 \%$ & \multirow{2}{*}{$<0.001$} \\
\hline & & $(2.58 \%-3.70 \%)$ & $(4.54 \%-7.16 \%)$ & \\
\hline \multirow{4}{*}{ PML } & \multirow{2}{*}{$\begin{array}{l}\text { Severe to } \\
\text { moderate }\end{array}$} & $4.24 \%$ & $1.52 \%$ & \multirow{2}{*}{$<0.001$} \\
\hline & & $(3.22 \%-5.26 \%)$ & $(0.97 \%-2.02 \%)$ & \\
\hline & \multirow{2}{*}{$\begin{array}{l}\text { Moderate to } \\
\text { remission }\end{array}$} & $2.09 \%$ & $3.26 \%$ & \multirow{2}{*}{0.158} \\
\hline & & $(1.44 \%-2.74 \%)$ & $(1.76 \%-4.76 \%)$ & \\
\hline \multirow{4}{*}{ Lymphoma } & \multirow{2}{*}{$\begin{array}{l}\text { Severe to } \\
\text { moderate }\end{array}$} & $4.93 \%$ & $3.60 \%$ & \multirow{2}{*}{0.230} \\
\hline & & $(3.46 \%-6.40 \%)$ & $(2.08 \%-5.10 \%)$ & \\
\hline & \multirow{2}{*}{$\begin{array}{l}\text { Moderate to } \\
\text { remission }\end{array}$} & $1.96 \%$ & $5.46 \%$ & \multirow{2}{*}{$<0.001$} \\
\hline & & $(1.25 \%-2.68 \%)$ & $(4.20 \%-6.76 \%)$ & \\
\hline
\end{tabular}

aSerious infection and lymphoma risks are defined as probability of treatmentrelated death within 10 years of initiating treatment. PML risk is defined as probability of treatment-related death or severe disability within 10 years of initiating treatment.

${ }^{b}$ Middle-aged patient was defined in the gastroenterologist survey as a male aged 45 years with 1 previous Crohn's disease surgery.

${ }^{c}$ MARs for middle-aged patients in the patient survey represent male patients aged 40 to 50 years with 1 previous surgery and were calculated as the highest level of SAE risk that subjects would accept in return for a given improvement in efficacy. ${ }^{d} P$ value using a 2-tailed test assuming a $z$ distribution.

$M A R=$ maximum acceptable risk; $P M L=$ progressive multifocal leukoencephalopathy; SAE= serious adverse event.

the possibility that early, aggressive or "top down" therapy may offer a chance to improve long-term outcomes. ${ }^{21}$ For this reason, early aggressive therapy, although not currently accepted practice, is of great interest as a possible future direction for treatment. The potential for better long-term outcomes directly applies to younger adult patients for whom the use of biologic therapy early in disease (before complications arise) may offer superior long-term efficacy. The present study found that among gastroenterologists, preference weights for the younger and middle-aged patient profiles are similar. Our results also indicate that gastroenterologists are more risk averse for patients who are not severely ill. On average, patients may, in fact, be more receptive to early aggressive or "top-down" therapy for moderate symptoms than their physicians. However, early aggressive therapy represents off-label use at the present time. Current labeled indications for TNF blockers are limited to patients with moderately to severely active disease who have had an inadequate response to conventional therapy. ${ }^{8-11}$ In addition, adalimumab is "indicated for reducing signs and symptoms and inducing clinical remission in these patients if they have also lost response to or are intolerant to infliximab,"11 and natalizumab is indicated only for patients with an inadequate response to TNF blockers. ${ }^{9}$ 
A hurdle for improving Crohn's disease treatment will be to accurately communicate risks to patients and judge whether early treatment that can improve long-term outcomes is likely to yield long-term benefits that justify the risk. Developing tools to communicate the risk of disease progression, advantages of aggressive therapy, and potential side effects will be critical to facilitate informed, preference-based treatment decisions. Ultimately, of course, these decisions must be made jointly between gastroenterologists and patients on an individual basis.

The findings of the present study suggest that, on average, both patients and gastroenterologists are willing to accept risks of SAEs, including disability or death, for therapies that offer significant therapeutic benefit. If patient populations that have the most to gain from therapy can be identified, patients and gastroenterologists may be more willing to accept treatmentrelated risks to achieve those benefits.

\section{Limitations}

First, although conjoint analysis methods are widely used in health economics and in other applications, they have limitations. One inherent limitation is that conjoint trade-off tasks ask subjects to evaluate hypothetical treatments and, in the case of the gastroenterologist survey, hypothetical patients as well. Such tradeoffs are intended to simulate realistic clinical decisions, but do not have the same clinical, financial, and emotional consequences of actual decisions. Thus differences can arise between stated and actual choices. We attempted to minimize such potential differences by offering alternatives that mimic real-world tradeoffs as closely as possible.

Second, we report only mean values for risk-tolerance estimates for a particular sample of gastroenterologists. Individual gastroenterologists' and patients' risk tolerance may be greater or less than these estimates, and our results should not be interpreted as a guide to therapeutic practice.

Third, it is not clear whether gastroenterologists' stated benefit-risk tradeoff preferences indicate their appraisal of their patients' risk tolerance, their personal risk tolerance, or some combination of considerations. Gastroenterologists' preferences may be influenced by their personal experiences in treating patients, including the distribution of symptom severity. However, we found no significant differences in gastroenterologists' judgments about appropriate treatment for the 3 patient profiles based on percentage of patients treated by disease severity.

A fourth and related limitation is the low response rate in the gastroenterologist study. Our final sample sizes were powered sufficiently to achieve reasonable CIs around parameter estimates. However, it is not possible to obtain a true random sample of practicing gastroenterologists willing to fill out a benefit-risk tradeoff survey. Although the study investigators polled a large gastroenterologist panel and offered reasonable compensation (\$75) for taking the survey, the survey response rate was less than $10 \%$. There is no practical way of directly assessing possible selection bias. On the other hand, we found no statistically significant associations between gastroenterologists' professional evaluations of hypothetical treatment outcomes and differences in practice patterns, years of practice, type of practice, and other observables. To the extent that the selection mechanism was determined by such factors, it had no significant influence on our estimates of mean physician risk tolerance.

Fifth, evaluating tradeoffs involving multiple efficacy and SAE risks can be cognitively challenging. Our survey included tests for subject consistency. The results of the internal validity tests in the gastroenterologist survey were similar to those of the patient survey. The results of the internal validity tests compare favorably with those of other studies. ${ }^{22,23}$ In this study, gastroenterologists and patients performed better than patients with diabetes and bipolar disorder in other choice-format conjoint health surveys. ${ }^{22,23}$ However, unlike these previous studies, we found in the present study that excluding gastroenterologists who failed the logic test improved the precision of the estimates. We also included statistical controls in the present study analysis to correct for any biases that may have resulted from subjects who focused exclusively on symptom severity by consistently selecting the treatment alternative that produced the better efficacy outcome, regardless of the associated treatment risk. To the extent that these gastroenterologists responses actually indicate a strong preference for reductions in symptom severity and a high tolerance for treatment-related adverse event risks, these statistical controls resulted in lower MAR estimates.

\section{Conclusions}

Several recent studies have estimated patients' benefit-risk preferences for pharmaceutical and biological treatments. ${ }^{15,24,25}$ However, to our knowledge this was the first study to use similar methods to compare risk tolerance estimates between gastroenterologists and patients with Crohn's disease. Gastroenterologists and patients indicated a willingness to accept clinically meaningful tradeoffs between better efficacy and treatment-related mortality risks in their responses to a series of constructed treatment decisions. More importantly, gastroenterologists and patients disagreed about how much risk is tolerable for improvements in efficacy. In exchange for improvements from severe to moderate symptoms for the middle-aged patient profile, gastroenterologists were significantly more tolerant than patients of treatment risks of serious infection and PML, but not lymphoma. In contrast, in exchange for improvements from moderate symptoms to remission for the same patient profile, patients were significantly more tolerant than gastroenterologists of treatment risks of serious infection and lymphoma, but not PML. 


\section{Authors}

F. REED JOHNSON, PhD, is Distinguished Fellow and Senior Economist; and A. BRETT HAUBER, PhD, is Global Head and Senior Economist, RTI International Health Solutions, Research Triangle Park, North Carolina. SEMRA ÖZDEMIR, MS, is a student, University of North Carolina at Chapel Hill, Chapel Hill, North Carolina. COREY A. SIEGEL, MD, is Director, Inflammatory Bowel Disease Center, Dartmouth-Hitchcock Medical Center, Lebanon, New Hampshire. STEVEN HASS, PhD, is Director, Global HEOR Neuroscience, Abbott Laboratories, Abbott Park, Illinois. At the time of the study, Hass was employed by Elan Pharmaceuticals. BRUCE E. SANDS, MD, is Assistant Professor of Medicine, Massachusetts General Hospital and Harvard Medical School, Boston, Massachusetts.

AUTHOR CORRESPONDENCE: F. Reed Johnson, PhD, RTI International Health Solutions, 200 Park Offices Drive, APT 204, Research Triangle Park, NC 27709. Tel: 919.541.5958; Fax: 919.541.7222.Email:frjohnson@rti.org.

\section{DISCLOSURES}

This study was funded in part by a contract with Elan Pharmaceuticals, San Francisco, California and Biogen Idec, Cambridge, Massachusetts.

Results were presented in part at the International Society for Pharmacoeconomics and Outcomes Research, Dublin, Ireland, October 22, 2007. Siegel presented a portion of the study results to the Gastrointestinal Drugs Advisory Committee and the Drug Safety and Risk Management Advisory Committee of the U.S. Food and Drug Administration in August 2007 in its consideration of new drug application number (BLA) 125104 for drug TYSABRI (natalizumab) for the treatment of moderate to severe Crohn's disease.

Hass and Sands were primarily responsible for concept and design, assisted by Hauber and Johnson. Ödemir, Hauber, and Johnson performed the data collection. Johnson, Hauber, and Özdemir were primarily responsible for data interpretation. Johnson wrote the manuscript, with the assistance of Hauber and Özdemir, and revised the manuscript, with the assistance of Siegel.

\section{ACKNOWLEDGEMENTS}

We would like to thank Carol Mansfield, PhD, RTI International, for her help in developing and pre-testing the survey instruments for the patient sample. We also would like to thank Ateesha Mohamed, MS, RTI International, and particularly Lauren Donnalley, BA, RTI International, for their assistance in revising the manuscript. We also are grateful to the editors of this journal for their extraordinary efforts in helping us communicate our results to the readers of this journal.

\section{REFERENCES}

1. Kappelman MD, Rifas-Shiman SL, Kleinman K, et al. The prevalence and geographic distribution of Crohn's disease and ulcerative colitis in the United States. Clin Gastroenterol Hepatol. 2007;5(12):1424-29.

2. Loftus CG, Loftus EV Jr., Harmsen WS, et al. Update on the incidence and prevalence of Crohn's disease and ulcerative colitis in Olmsted County, Minnesota, 1940-2000. Inflamm Bowel Dis. 2007;13(3):254-61. Available at: http://www3.interscience.wiley.com/cgi-bin/fulltext/114026649/PDFSTART. Accessed July 22, 2010.

3. Colombel JF, Sandborn WJ, Rutgeerts P, et al. Adalimumab for maintenance of clinical response and remission in patients with Crohn's disease: the CHARM trial. Gastroenterology. 2007;132(1):52-65.
4. Hanauer SB, Feagan BG, Lichtenstein GR, et al. Maintenance infliximab for Crohn's disease: the ACCENT I randomised trial. Lancet 2002;359(9317):1541-49.

5. Sandborn WJ, Feagan BG, Stoinov S, et al. Certolizumab pegol for the treatment of Crohn's disease. N Engl J Med. 2007;357(3):228-38. Available at: http://content.nejm.org/cgi/reprint/357/3/228.pdf. Accessed April 5, 2010. 6. Cosnes J, Nion-Larmurier I, Beaugerie L, Afchain P, Tiret E, Gendre JP. Impact of the increasing use of immunosuppressants in Crohn's disease on the need for intestinal surgery. Gut. 2005;54(2):237-41. Available at: http:// www.ncbi.nlm.nih.gov/pmc/articles/PMC1774826/?tool=pubmed. Accessed May 3, 2010.

7. Baert F, Caprilli R, Angelucci E. Medical therapy for Crohn's disease: topdown or step-up? Dig Dis. 2007;25(3):260-66

8. Cimzia (certolizumab pegol) for subcutaneous use. UCB, Inc. November 2009. Available at: http://www.cimzia.com/pdf/Prescribing_Information. pdf. Accessed July 22, 2010.

9. Tysabri (natalizumab) for intravenous use. Biogen Idec Inc. November 2009. Available at: http://www.tysabri.com/en_US/tysb/site/pdfs/TYSABRIpi.pdf. Accessed July 22, 2010

10. Remicade (infliximab) for intravenous use. Centocor Ortho Biotech Inc December 2009. Available at: http://www.remicade.com/remicade/assets/ HCP_PPI.pdf. Accessed July 22, 2010.

11. Humira (adalimumab) for subcutaneous use. Abbott Laboratories. November 2009. Available at: http://www.rxabbott.com/pdf/humira.pdf. Accessed July 22, 2010

12. Johnson FR, Özdemir S, Mansfield C, et al. Crohn's disease patients' risk-benefit preferences: serious adverse event risks versus treatment efficacy. Gastroenterology. 2007;133(3):769-79.

13. Johnson FR, Özdemir S, Mansfield C, Hass S, Siegel CA, Sands BE. Are adult patients more tolerant of treatment risks than parents of juvenile patients? Risk Anal. 2009;29(1):121-36. Available at: http://www.ncbi.nlm.nih.gov/pmc/ articles/PMC2847437/pdf/nihms-184452.pdf. Accessed July 22, 2010.

14. Kuhfeld WF, Tobias RD, Garratt M. Efficient experimental design with marketing research applications. J Marketing Research. 1994;31:545-57.

15. Huber J, Zwerina K. The importance of utility balance in efficient choice designs. J Marketing Research. 1996;33:307-17.

16. Train K. Discrete Choice Methods with Simulation. Cambridge University Press: Cambridge, UK; 2003.

17. Train K, Sonnier G. Mixed logit with bounded distributions of correlated partworths. In: Scarpa R, Alberini A, eds. Applications of Simulation Methods in Environmental and Resource Economics. Dordrecht: Springer Publisher; 2005.

18. Hensher DA, Rose JM, Greene WH. Applied Choice Analysis: A Primer. Cambridge: Cambridge University Press; 2005.

19. Johnson FR, Van Houtven G, Özdemir S, et al. Multiple sclerosis patients' benefit-risk preferences: serious adverse event risks versus treatment efficacy. J Neurol. 2009;256(4):554-62.

20. Swait J, Louviere J. The role of the scale parameter in the estimation and comparison of multinomial logit models. J Marketing Research. 1993;30:305-14. 21. D'Haens G, Baert F, van Assche G, et al. Early combined immunosuppression or conventional management in patients with newly diagnosed Crohn's disease: an open randomised trial. Lancet. 2008;371(9613):660-67. 22. Johnson JR, Matthews KE. Sources and effects of utility-theoretic inconsistencies in stated-preference surveys. Am J Agricultural Econ. 2001;83(5):1328-33.

23. Johnson FR, Özdemir S, Manjunath R, Hauber AB, Burch SP, Thompson TR. Factors that affect adherence to bipolar disorder treatments: a stated preference approach. Med Care. 2007;45(6):545-52.

24. Hauber AB, Mohamed AF, Watson ME, Johnson FR, Hernandez JE. Benefits, risk, and uncertainty: preferences of antiretroviral-naive African Americans for HIV treatments. AIDS Patient Care STDS. 2009;23(1):29-34. 25. Hauber AB, Johnson FR, Fillit H, et al. Older Americans' risk-benefit preferences for modifying the course of Alzheimer's disease. Alzheimer Dis Assoc Disord. 2009;23(1):23-32. 